therefore, it may be safe to conclude that the results strongly supported the the above hypothesis.

Eventually, the same results also confirmed a hypothesis of Schumacher, et al. 1941 that migraine is primarily related to an unstable state of the autonomic nerve, and related to also psychological factors caused by imbalance of blood distribution localized at the base of brain.

(copo: coproporphyllin)

\title{
38. Neurolept-Analgesia in Intracranial Surgery
}

\author{
Mitsuo Satoh, Mitsuko Satoyoshi, Keiji Kaya, Ikuo Yamanaka, \\ Ryohei KaWAmura and Tomomichi Hiraiwa \\ Dept. of Anesthesiology, Juntendo University, School of Medicine
}

So-called neurolept-analgesia for the intracranial operations was successfully obtained by the intravenous administration of the Mixture 1, contained pethilorfan, hydergine, vesprine and atropine and of the Mixture 2, using gamma-hydroxybutyrate or butyrolactone, with supplementary use of local or light general nitrous oxide-oxygen anesthesia.

As compared with fluothane anesthesia, the respiratory, cardiovascular and metabolic changes were markedly reduced by neurolept-analgesia, though with spontaneous respiration slight tendency to respiratory acidosis was occasionally observed in the blood gas analysis.

Post-operative recovery was more rapid and uneventful. Only in some instances, retching and restlessness were observed with the Mixture 2 immediately after the operation.

\section{Histological Study on Cranial Sutures of Secondary Craniostenosis}

\author{
Susumu MrYataka, Shozo Yodóshi, Shozaburo Utsumi, \\ and Yutaka HoRI \\ 2nd Dept. of Surgery, Nara Medical College
}

In our clinic, it has been found $20 \%$ of cerebral palsied patients with craniostenotic states in their skull and sutures which craniotomy are effective. 